\title{
Relevance of Presenting Risks of Frailty, Sarcopaenia and Osteopaenia to Outcomes From Aneurysmal Subarachnoid Haemorrhage
}

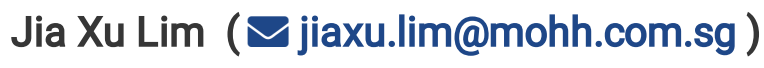

National Neuroscience Institute

Yuan Guang Lim

National Neuroscience Institute

A Aravin Kumar

National Neuroscience Institute

Tien Meng Cheong

National Neuroscience Institute

Julian Xinguang Han

National Neuroscience Institute

Min Wei Chen

National Neuroscience Institute

David Wei Wen

Singapore General Hospital

Winston Eng Hoe Lim

Singapore General Hospital

Ivan Hua Bak Ng

National Neuroscience Institute

Vincent Yew Poh Ng

National Neuroscience Institute

Ramez Kirollos

National Neuroscience Institute

Nicole Chwee Har Keong

National Neuroscience Institute

\section{Research Article}

Keywords: Frailty, temporalis muscle thickness, zygoma thickness, intracranial aneurysms, subarachnoid haemorrhage

Posted Date: September 29th, 2021 
DOI: https://doi.org/10.21203/rs.3.rs-939498/v1

License: (1) (7) This work is licensed under a Creative Commons Attribution 4.0 International License. Read Full License

Version of Record: A version of this preprint was published at BMC Geriatrics on April 16th, 2022. See the published version at https://doi.org/10.1186/s12877-022-03005-7. 


\section{Abstract}

Introduction

Aneurysmal subarachnoid haemorrhage (aSAH) is a condition with significant morbidity and mortality. In the context of acute brain injury, frailty, sarcopaenia and osteopaenia have become increasing concerns. Multiple indices have been devised in various surgical specialties to predict outcome and guide management. In this study, we examined whether such markers have relevance towards outcomes from acute brain conditions, such as aSAH.

\section{Methods}

An observational study in a tertiary neurosurgical unit on 51 consecutive patients with ruptured aSAH was performed. We compared various frailty indices (modified frailty index 11 , and 5 , and the National Surgical Quality Improvement Program score [NSQIP]), temporalis (TMT) and zygoma thickness (markers of sarcopaenia and osteopaenia), against traditional markers (age, World Federation of Neurological Surgery and modified Fisher scale [MFS]) for aSAH outcomes.

Results

TMT was the best performing marker in our cohort with an AUC of 0.82 , Somers' D statistic of 0.63 and Tau statistic 0.25 . Of the frailty scores, the NSQIP performed the best (AUC 0.69, Somer's D 0.40, Tau 0.16), at levels comparable to traditional markers of aSAH, such as MFS (AUC 0.68, Somer's D 0.43, Tau 0.17). After multivariate analysis, patients with TMT $\geq 5.5 \mathrm{~mm}$ (defined as non-frail), were less likely to experience complications (OR 0.20 [0.06 - 0.069], $p=0.011$ ), and had a larger proportion of favourable mRS on discharge $(95.0 \%$ vs. $58.1 \%, p=0.024)$ and at 3 -months $(95.0 \%$ vs. $64.5 \%, p=0.048)$. However, the gap between unfavourable and favourable mRS was insignificant at the comparison of 1-year outcomes.

Conclusion

TMT, as a marker of sarcopaenia, correlated well with the presenting status, and outcomes of aSAH. Frailty, as defined by NSQIP, performed at levels equivalent to aSAH scores of clinical relevance, suggesting that, in patients presenting with acute brain injury, both non-neurological and neurological factors were complementary in the determination of eventual clinical outcomes. Further validation of these markers, in addition to exploration of other relevant frailty indices, may help to better prognosticate aSAH outcomes and allow for a precision medicine approach to decision making and optimization of best outcomes

Trial registration

Not applicable

\section{Background}


Aneurysmal subarachnoid haemorrhage (aSAH) is a condition with significant morbidity and mortality [1], and is associated with substantial economic and disease burden [2]. The decision-making process behind the management of aSAH is complex with outcomes being influenced by the interaction between disease, patient, and doctor factors. It is a process of managing not only the primary brain injury caused during the rupture of the aneurysm, but also balancing the risk of intervention versus rerupture, as well as monitoring for and treatment of the complications of the rupture, including delayed cerebral ischemia. There is a need to triage patients appropriately to avoid over- or under-treating patient cohorts. Age, and grading scales such as the World Federation of Neurosurgical Societies (WFNS) [3] and modified Fisher scale [4], have been shown to be good prognosticators of outcomes and mortality in this condition, and proven utility in guiding treatment intent.

Across the spectrum of surgical interventions, frailty is a concept gaining momentum within the medical community due to the emerging evidence regarding the relevance of frailty risks towards both perioperative and longer-term adverse outcomes.[5-8]. Defined as a "biologic syndrome of decreased reserve and resistance to stressors, frailty is thought to result from cumulative declines across multiple physiological systems [9]." Multiple frailty scores exist, with various forms of clinical and instrumental assessment of each of the domains involved, contextualised in various forms of specialties [10]. The modified frailty index - 11 [11] (MFI-11), MFI-5 [12], and the National Surgical Quality Improvement Program (NSQIP) score [13], are three scores derived from the American College of Surgeons NSQIP database [14], that were shown to have strong predictive ability amongst various surgical specialties. Other indices include the clinical frailty score [15], risk analysis index [16], hospital frailty risk score [17], and the FRAIL questionnaire [18], which predicts survival and complications for elective surgery; 30-day mortality and readmission, and duration of hospital stay in the elderly; functional outcome and mortality in elderly trauma patients, respectively. In neurosurgery, the concept of frailty has been explored in various subspecialty conditions including brain tumour [19, 20], chronic subdural haematoma [21], and spine surgery [22-24]. Although some work has been published on aSAH in the frail $[25,26]$ and in the elderly $[27,28]$, there has been no study comparing the various indices on the outcomes of this condition.

Sarcopaenia and osteopaenia, the loss of muscle and bone mass, has been noted to be associated with frailty $[29,30]$. Temporalis thickness (TMT), a surrogate marker of sarcopaenia, have been shown to correlate with outcomes of various forms of cranial neurosurgery, including glioblastoma [31-33] and various types of brain metastasis [34-36]. TMT has also been noted to be associated with the presentation and functional outcome on discharge in aSAH [37, 38]. Zygoma thickness (ZGM), a proxy for osteopaenia, on the other hand, has been found to correlate with stay in hospital and intensive care as well as ventilator use in patients with mandibular fracture [39].

In this study, we aimed to investigate subarachnoid haemorrhage due to ruptured intracranial aneurysm and the effects of frailty (using established frailty indices: MFI-11, MFI-5, and NSQIP score) and markers of sarcopaenia and osteopaenia (TMT and ZGM), and compare them against traditional markers of aSAH severity (age, WFNS and Fisher grade). This has implications on the patient risk stratification when considering interventions for aSAH. 


\section{Methods}

Study design and patient selection

This was an observational study conducted by retrospective review of the electronic medical records of patients with aSAH in a tertiary neurosurgical unit between January 2014 to December 2015. Institutional review board review for consent waiver was obtained for this study. All adult patients with ruptured intracranial aneurysms managed in our centre during this period were included. We excluded patients managed with palliative intent and those lost to follow up.

Frailty score derivation

Frailty indices were employed in our study included MFI- $11^{10}, \mathrm{MFI}-5^{11}, \mathrm{NSQIP}{ }^{12}$. These indices were selected due to multiple studies demonstrating correlation with outcome and risk of complications across multiple surgical pathologies. In addition, these indices do not require extraordinary investigations such as grip strength or walking speed ${ }^{38}$, and hence could be reliably derived from patient's electronic medical records(see Table 1 (Supp) for Variables involved in selected frailty indices). 
Table 1

Characteristics of frail vs non-frail patients

\begin{tabular}{|c|c|c|c|c|c|c|}
\hline & & Overall & $\begin{array}{l}\text { Non-Frail } \\
(n=20)\end{array}$ & $\begin{array}{l}\text { Frail } \\
(n=31)\end{array}$ & OR (95\% Cl) & $\begin{array}{l}P \\
\text { Value }\end{array}$ \\
\hline Age & Mean \pm SD & $58.8 \pm 13.1$ & $\begin{array}{l}49.3 \pm \\
11.1\end{array}$ & $\begin{array}{l}65.0 \pm \\
10.6\end{array}$ & - & $\hat{0}_{0.001}$ \\
\hline Male gender & Frequency (\%) & 10 (19.6) & $6(30)$ & 4 (12.9) & $\begin{array}{l}2.89(0.70- \\
12)\end{array}$ & 0.16 \\
\hline Active smoking & Frequency (\%) & $4(10.3)$ & $1(5.9)$ & $3(13.6)$ & $\begin{array}{l}0.40(0.04- \\
4.19)\end{array}$ & 0.62 \\
\hline $\mathrm{mRS}$ & $\begin{array}{l}\text { Median (1Q - } \\
\text { 3Q) }\end{array}$ & $0(0-0)$ & $0(0-0)$ & $0(0-0)$ & - & 0.91 \\
\hline $\mathrm{CCl}$ & $\begin{array}{l}\text { Median (1Q - } \\
\text { 3Q) }\end{array}$ & $0(0-0)$ & $0(0-0)$ & $0(0-1)$ & - & 0.20 \\
\hline Presenting GCS & $\begin{array}{l}\text { Median (1Q - } \\
\text { 3Q) }\end{array}$ & $\begin{array}{l}15(9.25- \\
15)\end{array}$ & $\begin{array}{l}15(14- \\
15)\end{array}$ & $\begin{array}{l}14(9- \\
15)\end{array}$ & - & 0.052 \\
\hline Anisocoria & Frequency (\%) & $4(7.8)$ & $2(10.0)$ & $2(6.5)$ & $\begin{array}{l}1.61(0.21- \\
12)\end{array}$ & 0.64 \\
\hline WFNS grade & $\begin{array}{l}\text { Median (1Q - } \\
\text { 3Q) }\end{array}$ & $2(1-4)$ & $1(1-2)$ & $2(1-4)$ & - & 0.028 \\
\hline $\begin{array}{l}\text { Modified Fisher } \\
\text { scale }\end{array}$ & $\begin{array}{l}\text { Median (1Q - } \\
\text { 3Q) }\end{array}$ & $3(1-3)$ & $2.5(1-3)$ & $3(1-3)$ & - & 0.69 \\
\hline Hydrocephalus & Frequency (\%) & $16(31.4)$ & $6(30.0)$ & 10 (33.3) & $\begin{array}{l}0.86(0.25- \\
2.91)\end{array}$ & 0.80 \\
\hline Surgical clipping & Frequency (\%) & $26(51.0)$ & $13(65.0)$ & $13(41.9)$ & $\begin{array}{l}2.57(0.80- \\
8.23)\end{array}$ & 0.11 \\
\hline
\end{tabular}

Temporalis and zygoma thickness derivation

The TMT was derived from the presenting computed tomography angiography of the circle of Willis (CTA) of each patient in accordance with the description in previous studies ${ }^{35,36}$. ZGM, being adapted from on a previous study ${ }^{37}$, was measured at the midpoint of the zygomatic bone using the bone window axial image. The methodology for both measurements, including our refinements to derive TMT for this study, have been described in detail in the Supplementary Notes.

Data collection

The electronic medical records of each patient were accessed and baseline demographic information, including the age, gender, smoking status, premorbid functional status (based on modified Rankin scale [MRS]), medical comorbidities (based on Charlson comorbidity index [CCI]), and clinical variables required 
for each frailty index was recorded. Other information included presenting Glasgow coma scale (GCS), pupillary reactivity, severity of SAH (based on WFNS and Fisher grading), presence of hydrocephalus, and the type of intervention performed. WFNS grades of 1-3 are considered good grade.

The CTA findings of TMT and ZGM were evaluated by two study members (JXL and TMC) and the values were interrogated using Cohen's kappa for inter- and intra-rater agreement. The detailed description of this process as well as the cut-off derivation of TMT and ZGM are further detailed in the Supplementary Notes.

Inpatient and long-term outcomes were also documented. These included the NICU and overall length of stay, the presence of complications (any infective complications, intervention or non-intervention related; any delayed cerebral ischaemia; any overall complication that is directly due to intervention performed). The need for tracheostomy and ventriculoperitoneal shunt, discharge location, mortality, and functional status and various timepoints were also noted. Functional outcomes were measured using MRS and favourable MRS was defined using independent ambulation (MRS 0-3).

Statistical analysis

Receiver operating characteristic (ROC) analysis was performed for each marker versus the rate of favourable MRS on discharge, and model performance indices including area under the ROC curve (AUC), Somer's D statistic and Tau statistic, sensitivity and specificity along with their $95 \% \mathrm{Cl}$ were reported. The best marker and its most appropriate threshold were derived and used to evaluate the entire cohort of patients. The cohort will then be divided into frail and non-frail based on this. In addition, the agreement amongst each marker, using Spearman's correlation, was assessed.

Categorical variables were described using frequency and percent; and continuous variables were reported as mean and standard deviation (or median with 1st and 3rd quartiles, where appropriate). Baseline characteristics were compared between the frail and non-frail groups using Chi square test (or Fisher exact test, where appropriate) and two-sample t-test (or Mann-Whitney $\mathrm{U}$ test, depending on whether normality assumption was tenable) for categorical and continuous variables, respectively. Univariate logistic regression analysis was performed to investigate the association with baseline characteristics and clinical features. Multivariable logistic regression was then conducted to adjust for potential confounders identified from the literature or univariate analysis. In view of the small sample size, only WFNS grade was included in the adjustment for multivariable analysis. Un-adjusted and adjusted odds ratios (OR) and 95\% confidence intervals $(\mathrm{Cl})$ were reported.

Data analysis was performed using SAS software version 9.4 for Windows (Cary, NC: SAS Institute INC.) and statistical significance was set at $p<0.05$.

\section{Results}

Patient characteristics 
There were 60 patients with ruptured intracranial aneurysms managed during this period. After applying the exclusion criteria, 51 patients were analysed. There were $20(39.2 \%)$ and 31 patients $(60.8 \%)$ in the non-frail and frail groups, respectively. The differing frailty indices demonstrated moderate to good agreement in distinguishing between such groups (Table 4, Supp). Both groups differed significantly in age (mean \pm SD: $49.3 \pm 11.1$ vs. $65.0 \pm 10.6 \mathrm{~mm}, p<0.001$ ) and WFNS grading on presentation (median [1Q $-3 Q]$ : 1 [1-2] vs. $2[1-4], p=0.028)$. Otherwise, both groups were similar in terms of demographics, premorbid functional and medical status, and presenting clinical and radiological findings. Both groups also had a similar number of patients who underwent surgical clipping (Table 1 and Fig. 1).

AUC results and threshold

The best performing marker in our cohort was TMT, with an AUC of $0.83(0.70-0.94, p<0.001)$, Somers' D statistic of 0.63 and Tau's statistic of 0.25 , outperforming even the traditional markers such as WFNS, with an AUC of 0.76, Somer's D statistic of 0.53 and Tau's statistics of 0.22 ); for a comparison of AUC results and ROC charts, see Table 3, Supp and Fig. 2, respectively. Amongst the frailty markers, NSQIP score performed the best, with an AUC of $0.69(0.52-0.86, p=0.039)$, Somers' D statistic at 0.40 and Tau statistic at 0.16 . This has a similar predictive value to the traditional aSAH prognosticators, such as modified Fisher scale (AUC of 0.68 , Somers' D statistic of 0.43 and Tau's statistic of 0.17 ). MFI-11 and MFI-5, unexpectedly, did not perform well, with an unremarkable predictive value. The TMT cut-off thus derived was $5.5 \mathrm{~mm}$;patients with the larger TMT $<5.5 \mathrm{~mm}$ were defined as frail and $\geq 5.5 \mathrm{~mm}$ defined as non-frail. This threshold has a specificity of 0.93 , sensitivity of 0.51 , positive predictive value of 0.95 and negative predictive value of 0.42 . Of note, the Spearman's correlation amongst the three frailty markers were good (MFI-11 vs. MFI-5, $r=0.91 ;$ MFI-11 vs. NSQIP, $r=0.69 ;$ MFI-5 vs. NSQIP, $r=0.75$ ). 
Table 3

Long-term outcomes in non-frail vs frail patients

\begin{tabular}{|c|c|c|c|c|c|c|c|c|c|}
\hline & & & \multirow[t]{2}{*}{ Overall } & \multirow{2}{*}{$\begin{array}{l}\text { Non- } \\
\text { Frail } \\
(n= \\
20)\end{array}$} & \multirow{2}{*}{$\begin{array}{l}\text { Frail } \\
(\mathrm{n}= \\
31)\end{array}$} & \multicolumn{2}{|c|}{ Unadjusted } & \multicolumn{2}{|c|}{ Adjusted } \\
\hline & & & & & & $\begin{array}{l}\text { OR } \\
\text { (95\% } \\
\text { Cl) }\end{array}$ & $\begin{array}{l}\mathrm{P} \\
\text { Value }\end{array}$ & $\begin{array}{l}\text { OR } \\
\text { (95\% } \\
\mathrm{Cl})\end{array}$ & $\begin{array}{l}\mathrm{P} \\
\text { Value }\end{array}$ \\
\hline \multirow[t]{2}{*}{$\mathrm{mRS}$} & $\begin{array}{l}3 \\
\text { months }\end{array}$ & $\begin{array}{l}\text { Median } \\
(1 Q-3 Q)\end{array}$ & $\begin{array}{l}1(0- \\
3)^{(0-}\end{array}$ & $\begin{array}{l}1(0- \\
1)\end{array}$ & $\begin{array}{l}2(1- \\
4)\end{array}$ & - & 0.005 & - & 0.015 \\
\hline & 1 year & $\begin{array}{l}\text { Median } \\
(1 Q-3 Q)\end{array}$ & $\begin{array}{l}0(0- \\
2)\end{array}$ & $\begin{array}{l}0(0- \\
1)\end{array}$ & $\begin{array}{l}1(0- \\
4)\end{array}$ & - & 0.038 & - & 0.064 \\
\hline \multirow[t]{2}{*}{$\begin{array}{l}\text { Favourable } \\
\text { mRS }\end{array}$} & $\begin{array}{l}3 \\
\text { months }\end{array}$ & $\begin{array}{l}\text { Frequency } \\
(\%)\end{array}$ & $\begin{array}{l}39 \\
(76.5)\end{array}$ & $\begin{array}{l}19 \\
(95.0)\end{array}$ & $\begin{array}{l}20 \\
(64.5)\end{array}$ & $\begin{array}{l}10.5 \\
(1.23- \\
88)\end{array}$ & 0.017 & $\begin{array}{l}9.01 \\
(1.02- \\
79)\end{array}$ & 0.048 \\
\hline & 1 year & $\begin{array}{l}\text { Frequency } \\
(\%)\end{array}$ & $\begin{array}{l}42 \\
(82.4)\end{array}$ & $\begin{array}{l}19 \\
(95.0)\end{array}$ & $\begin{array}{l}23 \\
(74.2)\end{array}$ & $\begin{array}{l}6.61 \\
(0.76- \\
57)\end{array}$ & 0.072 & $\begin{array}{l}5.21 \\
(0.54- \\
50)\end{array}$ & 0.15 \\
\hline \multirow[t]{5}{*}{ Mortality } & 30 day & $\begin{array}{l}\text { Frequency } \\
\text { (\%) }\end{array}$ & $1(2.0)$ & $0(0)$ & $\begin{array}{l}1 \\
(3.2)\end{array}$ & - & 1.00 & - & 1.00 \\
\hline & $\begin{array}{l}6 \\
\text { months }\end{array}$ & $\begin{array}{l}\text { Frequency } \\
\text { (\%) }\end{array}$ & $1(2.0)$ & $0(0)$ & $\begin{array}{l}1 \\
(3.2)\end{array}$ & - & 1.00 & - & 1.00 \\
\hline & 1 year & $\begin{array}{l}\text { Frequency } \\
\text { (\%) }\end{array}$ & $2(3.9)$ & $0(0)$ & $\begin{array}{l}2 \\
(6.5)\end{array}$ & - & 0.52 & - & 1.00 \\
\hline & 3 year & $\begin{array}{l}\text { Frequency } \\
\text { (\%) }\end{array}$ & $3(5.9)$ & $0(0)$ & $\begin{array}{l}3 \\
(9.7)\end{array}$ & - & 0.29 & - & 1.00 \\
\hline & 5 year & $\begin{array}{l}\text { Frequency } \\
\text { (\%) }\end{array}$ & $5(9.8)$ & $0(0)$ & $\begin{array}{l}5 \\
(16.7)\end{array}$ & - & 0.14 & - & 1.00 \\
\hline
\end{tabular}

Inpatient outcomes

The non-frail patients were less likely to have delayed cerebral ischaemia (5.0 vs. 32.3\%, OR 0.11 [0.01$0.93], p=0.042$ ) or any form of complications (30.0 vs. $71.0 \%$, OR 0.20 [0.06-0.69], $p=0.011$ ). Both groups were comparable in terms of the rate of neurocardiac syndrome, infection, the need for tracheostomy and ventriculoperitoneal shunt. Both groups also had similar neuroscience intensive care unit (NICU) and overall length of stay and were equally likely to be discharged home or to a rehabilitation facility. The median MRS $(1[1-2.75]$ vs. $3[2-4], p=0.011)$ and frequency of favourable MRS on discharge (95.0 vs. $58.1 \%$, OR 12.2 [1.39-107], $p=0.024$ ) demonstrated greater favourable outcomes in the non-frail group, while inpatient mortality was similar between groups. This information is summarized in Table 2 . 
Table 2

Inpatient outcomes of non-frail vs frail patients

\begin{tabular}{|c|c|c|c|c|c|c|c|c|}
\hline & & Overall & Non- & Frail & Unadjus & & Adjuste & \\
\hline & & & $\begin{array}{l}(n= \\
20)\end{array}$ & $\begin{array}{l}(n= \\
31)\end{array}$ & $\begin{array}{l}\text { OR } \\
(95 \% \\
\text { Cl) }\end{array}$ & $\begin{array}{l}\mathrm{P} \\
\text { Value }\end{array}$ & $\begin{array}{l}\text { OR } \\
(95 \% \\
\mathrm{Cl})\end{array}$ & $\begin{array}{l}\mathrm{P} \\
\text { Value }\end{array}$ \\
\hline $\begin{array}{l}\text { Delayed cerebral } \\
\text { ischaemia }\end{array}$ & $\begin{array}{l}\text { Frequency } \\
(\%)\end{array}$ & $\begin{array}{l}11 \\
(21.6)\end{array}$ & $1(5.0)$ & $\begin{array}{l}10 \\
(32.3)\end{array}$ & $\begin{array}{l}0.11 \\
(0.013- \\
0.95)\end{array}$ & 0.034 & $\begin{array}{l}0.11 \\
(0.01- \\
0.93)\end{array}$ & 0.042 \\
\hline $\begin{array}{l}\text { Neurocardiac } \\
\text { syndrome }\end{array}$ & $\begin{array}{l}\text { Frequency } \\
(\%)\end{array}$ & $4(7.8)$ & $1(5.0)$ & $3(9.7)$ & $\begin{array}{l}0.49 \\
(0.05- \\
5.08)\end{array}$ & 1.00 & $\begin{array}{l}0.80 \\
(0.07- \\
9.77)\end{array}$ & 0.86 \\
\hline $\begin{array}{l}\text { Infective } \\
\text { complications }\end{array}$ & $\begin{array}{l}\text { Frequency } \\
(\%)\end{array}$ & $\begin{array}{l}21 \\
(41.2)\end{array}$ & $\begin{array}{l}6 \\
(30.0)\end{array}$ & $\begin{array}{l}15 \\
(48.4)\end{array}$ & $\begin{array}{l}0.46 \\
(0.14- \\
1.50)\end{array}$ & 0.19 & $\begin{array}{l}0.50 \\
(0.15- \\
1.68)\end{array}$ & 0.26 \\
\hline $\begin{array}{l}\text { Any overall } \\
\text { complications }\end{array}$ & $\begin{array}{l}\text { Frequency } \\
(\%)\end{array}$ & $\begin{array}{l}28 \\
(54.9)\end{array}$ & $\begin{array}{l}6 \\
(30.0)\end{array}$ & $\begin{array}{l}22 \\
(71.0)\end{array}$ & $\begin{array}{l}0.18 \\
(0.05- \\
0.60)\end{array}$ & 0.004 & $\begin{array}{l}0.20 \\
(0.06- \\
0.69)\end{array}$ & 0.011 \\
\hline Tracheostomy & $\begin{array}{l}\text { Frequency } \\
(\%)\end{array}$ & $\begin{array}{l}9 \\
(17.6)\end{array}$ & $\begin{array}{l}2 \\
(10.0)\end{array}$ & $\begin{array}{l}7 \\
(24.1)\end{array}$ & $\begin{array}{l}0.35 \\
(0.06- \\
1.89)\end{array}$ & 0.28 & $\begin{array}{l}0.48 \\
(0.08- \\
3.07)\end{array}$ & 0.44 \\
\hline $\begin{array}{l}\text { Ventriculopertioneal } \\
\text { shunt }\end{array}$ & $\begin{array}{l}\text { Frequency } \\
(\%)\end{array}$ & $\begin{array}{l}12 \\
(23.5)\end{array}$ & $\begin{array}{l}7 \\
(35.0)\end{array}$ & $\begin{array}{l}5 \\
(17.2)\end{array}$ & $\begin{array}{l}2.59 \\
(0.68- \\
9.79)\end{array}$ & 0.16 & $\begin{array}{l}5.23 \\
(0.97- \\
28)\end{array}$ & 0.056 \\
\hline NICU length of stay & $\begin{array}{l}\text { Median } \\
(1 Q-3 Q)\end{array}$ & $\begin{array}{l}8 \\
(4.5- \\
11)\end{array}$ & $\begin{array}{l}8(3- \\
11)\end{array}$ & $\begin{array}{l}8(5- \\
14)\end{array}$ & - & 0.73 & - & 0.85 \\
\hline $\begin{array}{l}\text { Overall length of } \\
\text { stay }\end{array}$ & $\begin{array}{l}\text { Median } \\
(1 Q-3 Q)\end{array}$ & $\begin{array}{l}24 \\
(16- \\
46.25)\end{array}$ & $\begin{array}{l}18 \\
(14.5- \\
33)\end{array}$ & $\begin{array}{l}28.5 \\
(16- \\
51.75)\end{array}$ & - & 0.24 & - & 0.53 \\
\hline $\begin{array}{l}\text { Discharged home/ } \\
\text { Rehabilitation }\end{array}$ & $\begin{array}{l}\text { Frequency } \\
(\%)\end{array}$ & $\begin{array}{l}46 \\
(90.2)\end{array}$ & $\begin{array}{l}19 \\
(95.0)\end{array}$ & $\begin{array}{l}27 \\
(93.1)\end{array}$ & $\begin{array}{l}1.41 \\
(0.12- \\
16)\end{array}$ & 1.00 & $\begin{array}{l}0.93 \\
(0.07- \\
12)\end{array}$ & 0.96 \\
\hline mRS on discharge & $\begin{array}{l}\text { Median } \\
(1 Q-3 Q)\end{array}$ & $\begin{array}{l}2(1- \\
4)\end{array}$ & $\begin{array}{l}1(1- \\
2.75)\end{array}$ & $\begin{array}{l}3(2- \\
4)\end{array}$ & - & 0.004 & - & 0.011 \\
\hline $\begin{array}{l}\text { Favourable mRS on } \\
\text { discharge }\end{array}$ & $\begin{array}{l}\text { Frequency } \\
(\%)\end{array}$ & $\begin{array}{l}37 \\
(72.5)\end{array}$ & $\begin{array}{l}19 \\
(95.0)\end{array}$ & $\begin{array}{l}18 \\
(58.1)\end{array}$ & $\begin{array}{l}13.7 \\
(1.63- \\
115)\end{array}$ & 0.004 & $\begin{array}{l}12.2 \\
(1.39- \\
107)\end{array}$ & 0.024 \\
\hline Mortality & $\begin{array}{l}\text { Frequency } \\
(\%)\end{array}$ & $1(2.0)$ & $0(0)$ & $1(3.2)$ & - & 1.00 & - & 1.00 \\
\hline
\end{tabular}

Long-term outcomes 
Frailty increased overall inpatient complications by nearly 2.5 fold and significantly distinguished unfavourable vs. favourable Modified Rankin Scale (MRS) upon discharge and at 3 months. With regards to long-term functional status, MRS at various time points favoured the non-frail patients, demonstrating both a better grade and a faster recovery. However, this gap reduced with time; the difference between unfavourable and favourable MRS for frail vs. non-frail patients was insignificant at comparison of one year outcomes. This can be seen in the Grotta chart in Fig. 3. Mortality at various short and long-term timepoints were similar amongst both groups. This is shown in Table 3.

\section{Discussion}

Multiple frailty indices and markers of sarcopaenia and osteopaenia have been investigated in the context of various surgical and neurosurgical disciplines. In this study, we utilized risk scores for frailty, and markers of sarcopaenia and osteopaenia, and compared them against traditional prognostication tools for outcomes following aSAH. We found that TMT was the best performing marker; it unexpectedly outperformed traditional aSAH markers, such as WFNS grading and correlated well with various inpatient and long-term outcomes. Of the frailty markers, NSQIP Score performed the best, at levels comparable to traditional aSAH markers with clinical relevance, such as Modified Fisher scale.

In the context of newer scales and novel measures gaining traction in clinical practice, such as frailty, traditional markers used to prognosticate the outcomes of aSAH, age, WFNS grade and Fisher scale remain relevant. This demonstrates the disproportionate role that the patients' age and presenting status play in the overall outcomes from this condition. Unexpectedly, MFI-11 and MFI-5 were not well able to predict the outcomes in aSAH. This was also reported in a previous study of aSAH [25]. There are a few potential reasons that this might be the case. The MFI-11 has an over-representation of cardiac (history of congestive heart failure, myocardial infarction, previous percutaneous procedures, or angina) and neurological related variables (impaired sensorium, transient ischaemic attack or cerebrovascular accident, neurological deficit after previous cerebrovascular accident). Although both systems are critical in the overall patient outcomes, MFI-11 does not cover other important domains of frailty such as nutritional status, mobility, strength, and mood [10]. MFI-5 [12], derived from MFI-11, purported to have the same predictive power, suffers from the same shortcomings. In addition, both scores did not represent other important physiological systems such as the renal and hepatic systems. The NSQIP score had a better performance than both MFIs (AUC 0.70 [0.54-0.86] vs. 0.58 [0.40-0.77] and 0.56 [0.37-0.74]) possibly due to its incorporation of other factors that were able to indicate the patient's non-neurological clinical status. These included variables that correspond to the patient's nutritional status (recent weight loss and body mass index), other important physiological systems (renal, hepatic, haematological, etc) and the acuteness of patient presentation (emergency case). The differences in performance between the NSQIP Score vs. MFI-11 and MFI-5 may well be attributable to the greater representation of systemic variables within the NSQIP Score, such as those correlated to susceptibility to infection (including systemic and wound infections, immunocompromised states such as disseminated cancer and steroid usage). Within the local context, frailty and mortality risks are known to be correlated with a high pathogenic load of latent infections [41]. 
Another reason that the MFI-11 and MFI-5 indices may fail to truly be indicative of the systemic load of comorbidities may be that these scores do not distinguish conditions by their severity. Patients with wellcontrolled hypertension, diabetes mellitus, congestive heart failure and chronic obstructive pulmonary disease were not distinguished in scoring from their poorly performing, chronically ill counterparts. Hence, MFI-11 and MFI-5 may not accurately reflect the supposed dynamic nature of frailty[42]. A further reason that frailty indices did not have the expected predictive value is the possibility that aSAH as an acute episode of brain injury overcomes the physiological reserves in a manner that having a frail or non-frail phenotype is inconsequential. This is likely true for patients who present with poor grade aSAH, where the major determinant for long-term good outcome remains the patients' neurological status following response to resuscitation and amenability to interventions. This explains the findings of why frailty indices may correlate well with elective surgeries, which are clinical situations that do not stress the physiological reserves to the same extent as acutely ruptured intracranial aneurysms. Interestingly, other authors have demonstrated the relevance of frailty to higher frequency of presentation with poor grade aSAH [25]. In our study, grade of aSAH was indeed distinguished by frail vs. non-frail groupings. However, despite the differing presentations, as well as the increased burden of complications in the former group, there was a narrowing of the gap between them for longer-term outcomes. This, coupled with the relative importance of non-neurological factors in the NSQIP Score strongly suggest that, in our cohort, it may be possible to use such scoring towards implementing targeted interventions (such as to optimize nutrition and infection risks) to improve patient trajectories following aSAH.

Non-neurological factors such as nutritional status, may also explain why sarcopaenia, as measured here using TMT, demonstrated such a strong correlation with aSAH outcomes. The TMT marker supported the notion that non-frail patients were more likely to present with a favourable WFNS grade, less likely to experience delayed cerebral ischaemia and inpatient complications, were discharged at a better functional status and with faster recovery. Our results are consistent with published literature, in which sarcopaenia has been found to be reflective of clinical status and recovery in studies of patients undergoing rehabilitation $[43,44]$. Deconditioning, which has been known to set in within the first day of admission [45] is demonstrative of the ability of sarcopaenia to reflect an acute to subacute context of frailty. In addition, our findings of sarcopaenia in this cohort are also consistent with local data demonstrating the correlation of measures of skeletal muscle mass with markers of subclinical vasculopathy, such as carotid intimamedia thickness, albeit in an asymptomatic cohort [46]. Its capacity to encompass risk factors from multiple frailty domains, whilst also describing the dynamics of the physiological response to stressors, may therefore make sarcopaenia desirable as both a marker of muscle loss, as well as a surrogate for more global notions of an acutely "frail state". Osteopenia, on the other hand, reacts much slower, possibly in the order of years. This is reflected in a study of the progression of osteopaenia in human immunodeficient virus infected patients using dual-energy X-ray absorptiometry [47]. Thus, it is not surprising that in acute non-traumatic brain injury, osteopaenia was not a good prognosticating factor for eventual clinical outcomes

There were two unexpected observations in our study amongst both groups with regards to the inpatient and long-term outcomes. Firstly, despite frail patients having up to four times the rate of complications 
compared to the non-frail patients, the length of stay in the NICU and the ward, and the proportion of patients discharged home or to a rehabilitation facility were similar. We attribute this to the prompt and aggressive subspecialist clinical management of aSAH complications such as delayed cerebral ischaemia, neurocardiac syndrome and infections. Secondly, although frail patients had a significantly larger proportion with unfavourable MRS on discharge, after a year of rehabilitation and community interventions, the gap between the frail and non-frail patients narrowed. Furthermore, the proportion of non-frail patients with favourable MRS did not change from discharge up to the 1-year follow up. This suggests that frailty alone should not be threshold at which the offer of clinical interventions should be decided. We hypothesise that the reason for this phenomenon was that both groups had a similar proportion of patients with the rehabilitation potential, as evidenced by the similar proportion of patients with favourable MRS at the 1-year interval. However, it may be that non-frail patients were more able to reach this potential in a shorter time duration due to their enhanced physiological reserves at presentation. Whilst it may not be possible to augment the reserves of frail patients, our results suggest that it may be possible to develop specific interventions to buffer them through an acute state of worsening frailty and sarcopaenia, in order to reach their potential for long-term good outcomes.

Our study limitations include to its retrospective nature and modest sample size. While we explored the possibility of using other notable frailty indices such as risk analysis index, hospital frailty risk score, and the FRAIL questionnaire, data gaps in important domains such as poor appetite, cognitive deterioration, a general feeling of fatigue, and walking distance, limited our efforts to do so successfully.Nevertheless, our study sheds light on use of the concept of frailty in the context of acute brain injury from aSAH. There is a need for the understanding of how best to apply both global surrogates and specific markers indicative of the state of acute to subacute frailty and to understand their relevance to specific surgical contexts [48-50].

\section{Conclusion}

Our study has demonstrated the immediate relevance for the utility of TMT as both a marker of presenting risks of sarcopaenia, and its impact upon outcomes following aSAH. Future work would include using other markers of sarcopaenia and examining patients with unruptured aneurysms to establish baseline thresholds for these factors as an important comparator cohort. As NSQIP score for frailty performs at similar levels to traditional prognostication tools for aSAH outcomes, it may be useful to further develop and refine its use within the context of a SAH-specific frailty index. Markers of sarcopaenia outperformed osteopaenia; TMT strongly correlated with the presenting status, inpatient, and long-term outcomes of aSAH, outperforming traditional tools. In this context of acute brain injury, TMT and NSQIP scoring may be valuable as as part of a risk stratification strategy to develop interventions promoting patient trajectories towards their best potential for good outcomes intervention.

\section{Abbreviations}

CTA = computed tomography angiography; MFI = modified frailty index; mRS: modified Rankin scale; NSQIP= National Surgical Quality Improvement Program; SAH = subarachnoid haemorrhage; TMT = temporalis thickness; WFNS = World Federation of Neurological Surgeons; ZGM = zygoma thickness 


\section{Declarations}

\section{Ethics approval and consent to participate}

Ethics approval and consent waiver was obtained from the Singhealth Institutional Review Board $(2020 / 2885)$

Consent for publication

Not applicable

Availability of data and materials

The datasets used and/or analysed during the current study are available from the corresponding author on reasonable request.

Competing interests

The authors declare that they have no competing interests.

\section{Fundings}

Funded by National Medical Research Council Clinician Scientist Award (MOH-CSAINV18nov-0005). There was no involvement of the funding body in any part of the manuscript preparation.

\section{Author's contribution}

JXL conceptualised the study, performed data collection and analysis and wrote the original draft and participated in the editing process. YGL assisted in the data collection and review process. AAK participated in data collection and the review process. TMC was involved in the data collection, assisted in performed inter-rater assessment of the sarcopaenia and osteopaenia marker, and review process. JH, MWC, DW, WL, VN, RK reviewed the manuscript and assisted in editing and conceptualisation. MWC was involved in review and editing of the manuscript and conceptualisation. NK was involved in conceptualisation, writing and review and overall supervision of the project.

\section{Acknowledgements}

Not applicable

\section{References}

1. Nieuwkamp DJ, Setz LE, Algra A, et al. Changes in case fatality of aneurysmal subarachnoid haemorrhage over time, according to age, sex, and region: a meta-analysis. Lancet Neurol 2009;8:635642 
2. Rivero-Arias O, Gray A, Wolstenholme J. Burden of disease and costs of aneurysmal subarachnoid haemorrhage in the United Kingdom. Cost Eff Resour Alloc 2010;8:6

3. Rosen DS, Macdonald RL. Grading of subarachnoid hemorrhage: modification of the world federation of neurosurgical societies scale on the basis of data for a large series of patients. Neurosurg 2004;54:566-576

4. Ogilvy CS, Carter BS. A proposed comprehensive grading system to predict outcome for surgical management of intracranial aneurysms. Neurosurg 1998;42:959-968

5. Dasgupta M, Rolfson DB, Stolee $\mathrm{P}$, et al. Frailty is associated with postoperative complications in older adults with medical problems. Arch Gerontol Geriatr 2009;48:78-83

6. Makary MA, Seger DL, Pronovost PJ, et al. Frailty as a predictor of surgical outcomes in older patients. J Am Coll Surg 2010;210:901-908

7. Saxton A, Velanovich V. Preoperative frailty and quality of life as predictors of postoperative complications. Ann Surg 2011;253:1223-1229

8. Sun $X$, Shen Y, Ji M, et al. Frailty is an independent risk factor of one-year mortality after elective orthopedic surgery: a prospective cohort study. Aging 2021;13:7190-7198

9. Fried LP, Tangen CM, Walston J, et al. Frailty in older patients: evidence for a phenotype. J Gerontol A Biol Sci Med 2001;56:146-156

10. de Vries NM, Staal JB, van Ravensberg CD, et al. Outcome instruments to measure frailty: a systematic review. Ageing Res Rev 2011;10:104-114

11. Velanovich V, Antoine H, Swartz A, et al. Accumulating deficits model of frailty and postoperative mortality and morbidity: its application to a national database. J Surg Res 2013;183:104-110

12. Subramaniam S, Aalberg JJ, Soriano RP, et al. New 5-factor modified frailty index using American College of Surgeons NSQIP Data. J Am Coll Surg 2018;226:173-182

13. Tomlinson SB, Piper K, Kimmell KT, et al. Preoperative frailty score for 30-day morbidity and mortality after cranial neurosurgery. World Neurosurg 2017;107:959-965

14. https://

15. Rockwood K, Song X, MacKnight C, et al. A global clinical measure of fitness and frailty in elderly people. CMAJ 2005;173:489-495

16. Hall DE, Arya S, Schmid KK, et al. Development and initial validation of the risk analysis index for measuring frailty in surgical populations. JAMA Surg 2017;152:175-182

17. Gilbert T, Neuburger J, Kraindler J, e al. Development and validation of a hospital frailty risk score focusing on older people in acute care settings using electronic hospital records: an observational study. Lancet 2018;391:1775-1782

18. Maxwell CA, Dietrich MS, Miller RS. The FRAIL questionnaire: a useful tool for bedside screening of geriatric trauma patients. J Trauma Nurs 2018;25:242-247

19. Cloney M, D’ Amico R, Lebovic J, et al. Frailty in geriatric glioblastoma patients: a predictor of operative morbidity and outcome. World Neurosurg 2016;89:362-367 
20. Youngerman BE, Neugut Al, Yang J, et al. The modified frailty index and 30-day adverse events in oncological neurosurgery. J Neuro Oncol 2018;136:197-206

21. Shimizu K, Sadatomo T, Hara T, et al. Importance of frailty evaluation in the prediction of the prognosis of patients with chronic subdural haematoma. Geriatr Gerontol Int 2018;18:1173-1176

22. Miller EK, Neuman BJ, Jain A, et al. An assessment of frailty as a tool for risk stratification in adult spinal deformity surgery. Neurosurg Focus 2017;43:E3

23. Flexman AM, Charest-Morin R, Stobart $L$, et al. Frailty and postoperative outcomes in patients undergoing surgery for degenerative spine disease. J Spine 2016;16:1315-1323

24. Shin Jl, Kothari P, Phan K, et al. Frailty index as a predictor of adverse postoperative outcomes in patients undergoing cervical spine fusion. Spine 2018;42:304-310

25. Mclntyre MK, Gandhi C, Long A, et al. Age predicts outcomes better than frailty following aneurysmal subarachnoid hemorrhage: a retrospective cohort analysis. Clin Neurol Neurosurg 2019;187:105558

26. McIntyre MK, Gandhi C, Dragonette J, et al. A comparison of frailty indices in predicting length of inpatient stay and discharge destination follow angiogram-negative subarachnoid hemorrhage. $\mathrm{Br} \mathrm{J}$ Neurosurg 2020;25:1-6

27. Yue Q, Liu Y, Leng B, et al. A prognostic model for early post-treatment outcome of elderly patients with aneurysmal subarachnoid hemorrhage. World Neurosurg 2016,95:253-261

28. Virta JJ, Satopaa J, Luostarinen T, et al. One-year outcome after aneurysmal subarachnoid hemorrhage in elderly patients. World Neurosurg 2020;143:e334-e343

29. Frisioli A, Chaves PH, Ingham SJM, et al. Severe osteopaenia and osteoporosis, sarcopaenia, and frailty status in community-dwelling older women: results from the Women Health and Aging Study (WHAS) II. Bone 2011;48:952-7

30. Hasegawa Y, Yoshida M, Sato A, et al. Temporal muscle thickness as a new indicator of nutritional status in older individuals. Geriatr Gerontol Int 2019;19:135-40

31. An G, Ahn S, Park JS, et al. Association between temporal thickness and clinical outcomes in patients with newly diagnosed glioblastoma. J Cancer Res Clin Oncol 2021;147:901-909

32. Havva YC, Hale CE. Is temporal muscle thickness a survival predictor in newly diagnosed glioblastoma multiforme? Asia Pac J Clin Oncol 2020;16:e223-e227

33. Furtner J, Genbrugge E, Gorlia T, et al. Temporal muscle thickness is an independent prognostic marker in patients with progressive glioblastoma: translational imaging analysis of the EORTC 26101 trial. Neuro Oncol 2019;21:1587-94

34. Furtner J, Berghoff AS, Albtoush OM, et al. Survival prediction using temporal muscle thickness measurements on cranial magnetic resonance images in patients with newly diagnosed brain metastases. Eur Radiol 2017;27:3167-73

35. Havva YC, Hale CE. The prognostic effects of temporal muscle thickness and inflammatory-nutritional parameters on survival in lung cancer patients with brain metastasis. Turk J Oncol 2020;35:119-26

36. Furtner J, Berghoff AS, Schopf V, et al. Temporal muscle thickness is an independent prognostic marker in melanoma patients with newly diagnosed brain metastases. J Neuro Oncol 2018;140:173-8 
37. Katsuki M, Suzuki Y, Kunitoki K, et al. Temporal muscle as an indicator of sarcopaenia is independently associated with Hunt and Kosnik grade on admission and the modified Rankin scale at 6 months of patients with subarachnoid haemorrhage treated by endovascular coiling. World Neurosurg 2020;137:e526-e534

38. Katsuki M, Yamamoto Y, Uchiyama T, et al. Clinical characteristics of aneurysmal subarachnoid haemorrhage in the elderly over 75; would temporal muscle be a potential prognostic factor as an indicator of sarcopaenia? Clin Neurol Neurosurg 2019;186:105535

39. Lisiecki J, Zhang P, Wang L, et al. Morphomic measurement of the temporalis muscle and zygomatic bone as novel predictors of hospital-based clinical outcomes in patients with mandible fracture. $J$ Craniofac Surg 2013;24:1577-81

40. Pazniokas J, Gandhi C, Theriault B, et al. The immense heterogeneity of frailty in neurosurgery: a systematic literature review. Neurosurg Rev 2021;44:189-201

41. Ng TP, Lu Y, Tan CTY, et al. Pathogenic load and frailty in older adults: Singapore longitudinal ageing study. Aging 2020;12:22139-22151

42. Gobbens RJ, Luijkx KG, Wijnen-Sponselee MT, et al. Toward a conceptual definition of frail community dwelling older people. Nurs Outlook 2010;58:76-86

43. Yoshimura $Y$, Wakabayashi $H$, Bise $T$, et al. Prevalence of sarcopenia and its association with activities of daily living and dysphagia in convalescent rehabilitation ward inpatients. Clin Nutr 2018;37:20222028

44. Yoshimura $\mathrm{Y}$, Wakabayashi $\mathrm{H}$, Bise $\mathrm{T}$, et al. Sarcopenia is associated with worse recovery of physical function and dysphagia and a lower rate of home discharge in Japanese hospitalized adults undergoing convalescent rehabilitation. Nutr 2019;61:111-118

45. Arora A. 2017. https://www.bgs.org.uk/blog/sit-up-get-dressed-keep-moving-the-campaign-everyone-istalking-about

46. Lim SL, Liu X, Gao Q, et al. Subclinical vasculopathy and skeletal muscle metrics in the Singapore longitudinal ageing study. Aging 2021;13:14768-14784

47. Negredo E, Bonjoch A, Gomez-Mateu M, et al. Time of progression to osteopenia/osteoporosis in chronically HIV-infected patients: screening DXA scan. PLoS One 2012;7:e46031

48. Miller EK, Vila-Casademunt A, Neuman BJ, et al. External validation of the adult spinal deformity frailty index. Eur Spine J 2018;27:2331-2338

49. Passoas PG, Bortz CA, Segreto FA, et al. Development of a modified cervical deformity frailty index: a streamlined clinical tool for preoperative risk stratification. Spine 2019;44:169-176

50. Massaad E, Williams N, Hadzipasic M, et al. Performance assessment of the metastatic spinal tumour frailty index using machine learning algorithms: limitations and future directions. Neurosurg Focus 2021;50:E5

51. McHugh ML. Interrater reliability: the kappa statistic. Biochem Med 2012;22:276-282

\section{Figures}




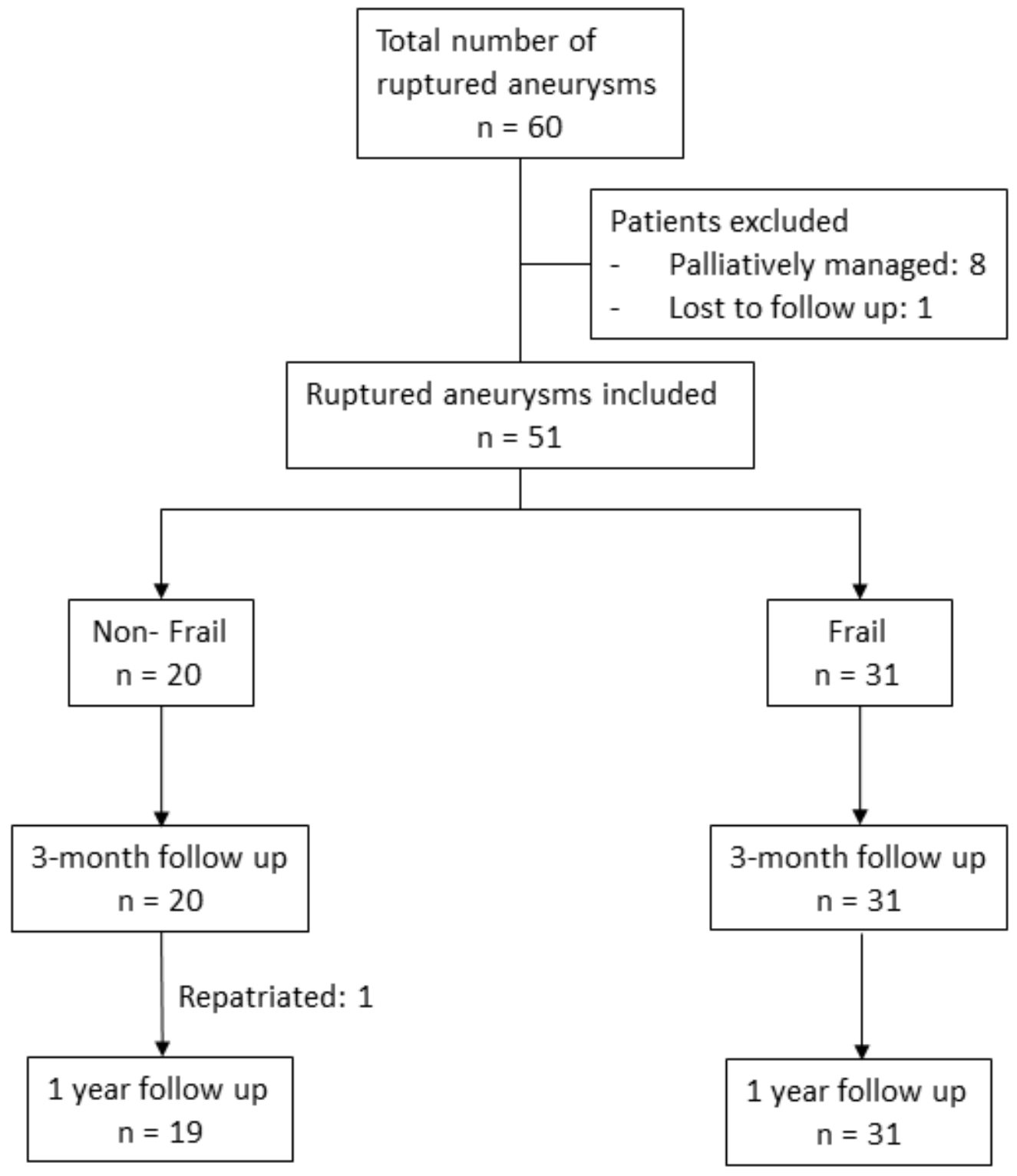

Figure 1

Patients and follow up at various timepoints 

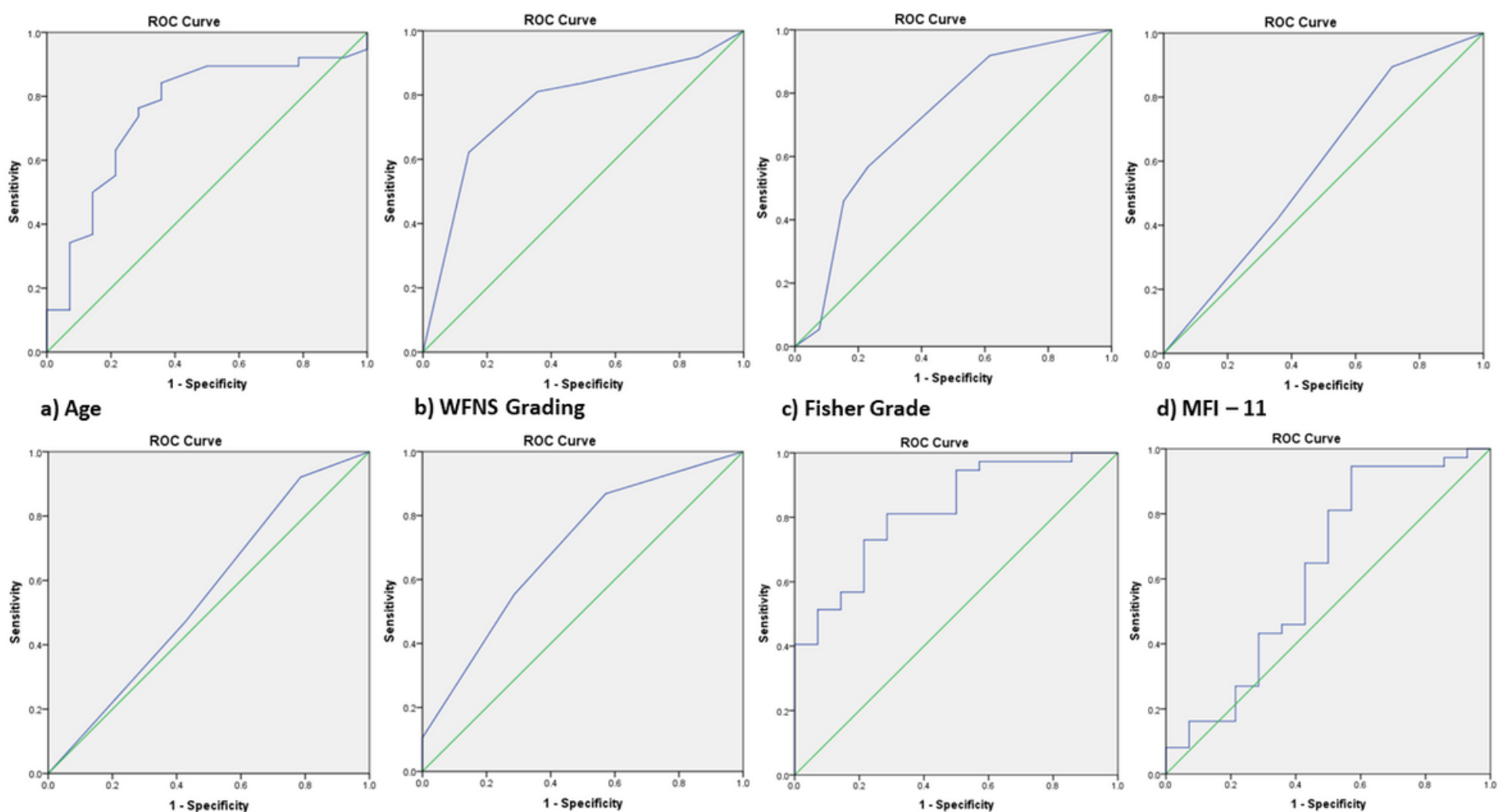

b) WFNS Grading

c) Fisher Grade
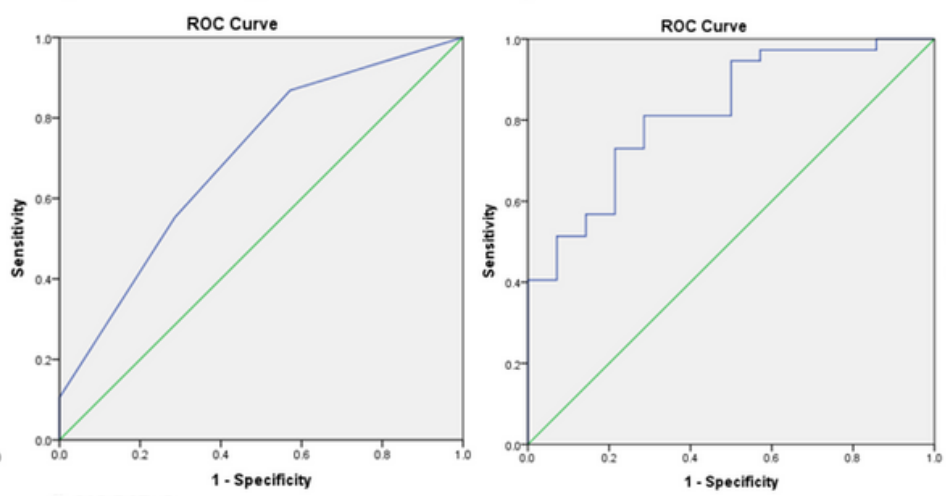

d) MFI - 11

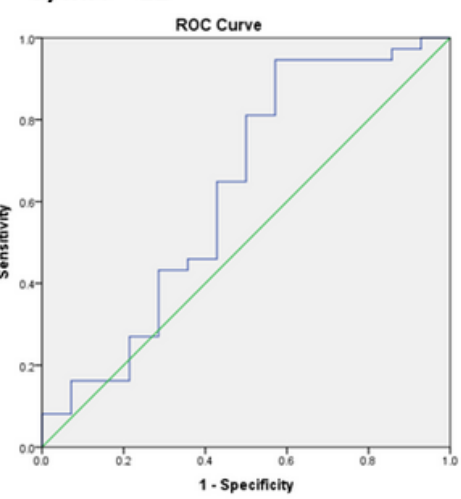

f) NSQIP Score

g) Temporalis Thickness

\section{Figure 2}

Receiver operating curve for a) age; b) WFNS; c) Fisher grade; d) MFI-11; e) MFI-5; f) NSQIP score; g) temporalis thickness; $h)$ zygoma thickness Area under curve $(95 \% \mathrm{Cl})$ of age: $0.76(0.60-0.91)$; WFNS grade: 0.77 (0.62 - 0.91); Fisher grade: 0.72 (0.54 - 0.89); MFI-11: 0.58 (0.40 - 0.77); MFI-5: 0.56 (0.37 $0.74)$; NSQIP score: $0.70(0.54-0.86)$; TMT: $0.82(0.70-0.94)$; ZGM: $0.62(0.44-0.82)$ respectively WFNS: World Federation of Neurological Surgeons: MFI: modified frailty index; NSQIP: National Surgical Quality Improvement Program; TMT: temporalis muscle thickness 
Frail Group: discharge MRS

Non-Frail Group: discharge MRS

Frail Group: 3-month MRS

Non-Frail Group: 3-month MRS

Frail Group: 1 year MRS

Non-Frail Group: 1 year MRS

$0 \%$

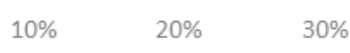

$\square$ MRS $0 \quad \square$ MRS

$40 \%$

$50 \%$

$60 \%$

$70 \%$

$\square$ MRS $4 \quad \square$ MRS $5 \quad \square$ MRS 6

\section{Figure 3}

Comparison of modified Rankin scale for frail and non-frail groups at various timepoints Oblique line demonstrates the threshold between favourable and unfavourable MRS (favourable MRS defined as $0-3$ ) mRS: modified Rankin scale

\section{Supplementary Files}

This is a list of supplementary files associated with this preprint. Click to download.

- SuppNotes.docx 